\title{
Characteristics of Carbon Nanospheres Prepared from Locally Deoiled Asphalt
}

\begin{abstract}
Mohammed Ibrahim Mohammed, Raheek Ismaeel Ibrahim, Luma Hussein Mahmoud, Mumtaz Abdulahad Zablouk, Neeran Manweel, and Abeer Mahmoud
\end{abstract}

Chemical Engineering Department, University of Technology, Baghdad, Iraq

Correspondence should be addressed to Raheek Ismaeel Ibrahim; doctorraheek@yahoo.com

Received 8 April 2013; Revised 19 June 2013; Accepted 20 June 2013

Academic Editor: Steven Suib

Copyright (c) 2013 Mohammed Ibrahim Mohammed et al. This is an open access article distributed under the Creative Commons Attribution License, which permits unrestricted use, distribution, and reproduction in any medium, provided the original work is properly cited.

\begin{abstract}
Iraqi deoil asphalt as a source of carbon is used to prepare the carbon nanospheres (CNS) by chemical vapor deposition (CVD) method. Asphalt after further chemical treatment to remove aromatic oil and impurities was crushed, weighted and evaporated under inert atmosphere using argon. The vapor/argon mixture was allowed to pass through high temperature zone $900^{\circ} \mathrm{C}$ in quartz tube over $\mathrm{CO} / \mathrm{Al}_{2} \mathrm{O}_{3}$ catalyst material. The carbon precipitated from the decomposition of asphalt vapor was collected and identified using atomic force microscope (AFM), scanning electron microscope (SEM), X-ray diffractometer (XRD), BET surface area technique and atomic force microscope. A sphere shape of carbon (94\%) with nanosize and diameter less than $100 \mathrm{~nm}$ with surface area of $360 \mathrm{~m}^{2} / \mathrm{g}$ has been obtained.
\end{abstract}

\section{Introduction}

Asphalt is a sticky, black, and highly viscous liquid or semisolid that is presented in most crude petroleum and in some natural deposits sometimes termed asphalt. In Iraq, asphalt (or asphalt cement) is the carefully refined residue from the distillation process of crude oils, and it forms about $2.2 \%$ of total residual content of crude oil.

Iraqi asphalt has a density $1.04 \mathrm{~g} / \mathrm{cm}^{3}$, softening point $50.4^{\circ} \mathrm{C}$, and several thousands of molecular weight, is rich with carbon (about 84\%), and is now usually used in construction, where it is used as the glue or binder for the aggregate particle.

Synthesis of spherical carbon nanospheres (CNS) and other structures of carbon has received a considerable attention in recent years because of their enormous potential in a wide spectrum of applications such as nanoadditives [1], energy storage [2-4], and separation technology $[5,6]$.

For the preparation of carbon nanospheres, different carbon sources such as graphite, petrochemicals, and organometallic compounds have been tested before. Some of these tests include chemical vapor deposition [7] , sol-gel emulsification [8], electro spraying [9], and arc discharge [10]
Synthesis of CNs from deoiled asphalt was reported by Fan et al. [11], and in their results carbon nanospheres synthesized from deoiled asphalt were spherical with uniform size and amorphous structure. However, our survey of available literature indicates that Iraqi asphalt has not been used as carbon precursor for the synthesis of carbon nanomaterials. Then the use of cheap material such as asphalt in production of carbon nanomaterials will have its economic reflection. During this work and for the first time, carbon nanospheres were synthesised utilizing Iraqi deoiled asphalt with some modification over previous methods.

\section{Experimental Work}

\subsection{Material}

2.1.1. Asphalt. Asphalt is supplied by a midland petroleum refinery company (Baghdad, Iraq). Table 1 shows some analytical data of asphalt.

2.1.2. Catalyst. For preparation of catalyst, a solution including $2.5 \mathrm{~g}$ of cobalt nitrate and $22 \mathrm{~g}$ of distilled water was prepared. The metal content of the solution was then impregnated on $10 \mathrm{~g}$ of high purity of $\mathrm{Al}_{2} \mathrm{O}_{3}$ beads of about 
TABLE 1: Physical properties of Iraqi asphalt (as received from supplier).

\begin{tabular}{lccccccc}
\hline $\begin{array}{l}\text { Specific gravity at } \\
15.6^{\circ} \mathrm{C}\end{array}$ & $\begin{array}{c}\text { Flash point } \\
{ }^{\circ} \mathrm{C}\end{array}$ & $\begin{array}{c}\text { Duct at } \\
25^{\circ} \mathrm{C}\end{array}$ & $\begin{array}{c}\text { \% Wt loss on } \\
\text { heat }\end{array}$ & $\begin{array}{c}\text { Soft point } \\
{ }^{\circ} \mathrm{C}\end{array}$ & $\begin{array}{c}\text { \%Wt. Sol. in } \\
\mathrm{CCL}_{4}\end{array}$ & $\begin{array}{c}\text { Solubility at } \\
{ }^{\circ} \mathrm{C} 25\end{array}$ & $\begin{array}{c}\mathrm{H}_{2} \mathrm{O} \text { Vol.\% } \\
1.04\end{array}$ \\
328 & 100 & 0.025 & 50.4 & 99.9 & 50 & NIL \\
\hline
\end{tabular}

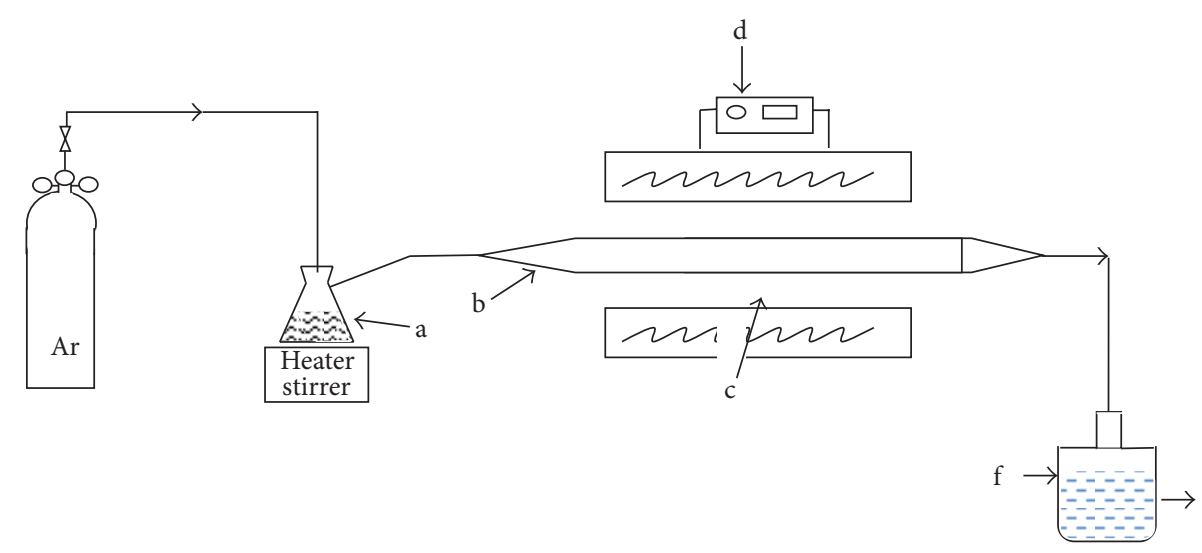

Figure 1: Experimental setup of CNS, CVD production rig. a: asphalt, b: quartz tube, c: tubular furnace, d: controller, e: catalyst boat, f: water trap.

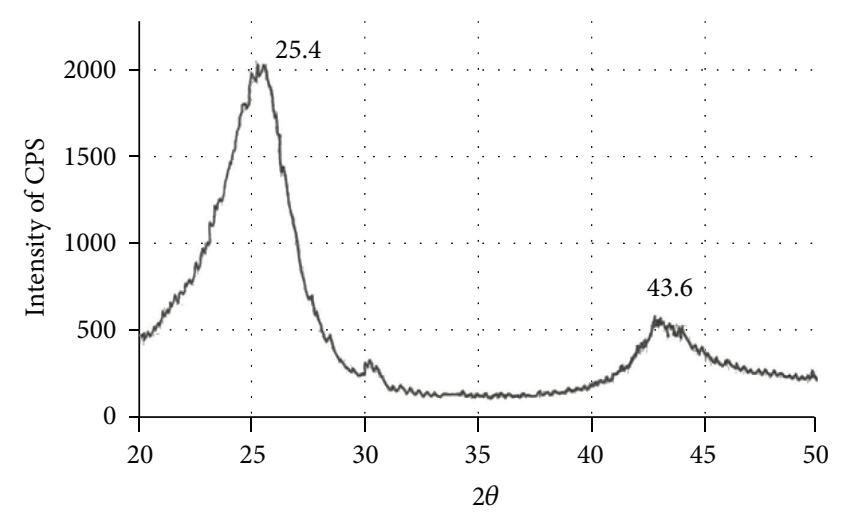

FiguRE 2: XRD pattern of the CNS powder.

$3 \mathrm{~mm}$ in diameter. The catalyst was then dried at $120^{\circ} \mathrm{C}$. for six hours. The calcination process was performed in a temperature-programmed electric tubular furnace at $450^{\circ} \mathrm{C}$ under a nitrogen atmosphere for 4 hours. The metal catalyst $\left(\mathrm{CO} / \mathrm{Al}_{2} \mathrm{O}_{3}\right)$ was then kept in desiccators under dry condition.

\subsection{Preparation of Carbon Nanospheres (CNSs)}

2.2.1. Preparation Deoiled Asphalt. In order to eliminate all of residual oil within the asphalt, $250 \mathrm{~g}$ of material (asphalt) was dissolved carefully in $500 \mathrm{~mL}$ of toluene using mechanical mixer. $200 \mathrm{~mL}$ of concentrated $\mathrm{H}_{2} \mathrm{SO}_{4}$ was added to the solution with continuous stirring till all the heavy sludge material is agglomerated and separated from the mixture as a gelatin mass. Furthermore, the product was filtered and washed with water until the $\mathrm{pH}$ of water reached 7 . Then the material was baked in oven for $2 \mathrm{~h}$ at $110^{\circ} \mathrm{C}$. Finally, the dried materials as deoiled asphalt were mechanically crushed

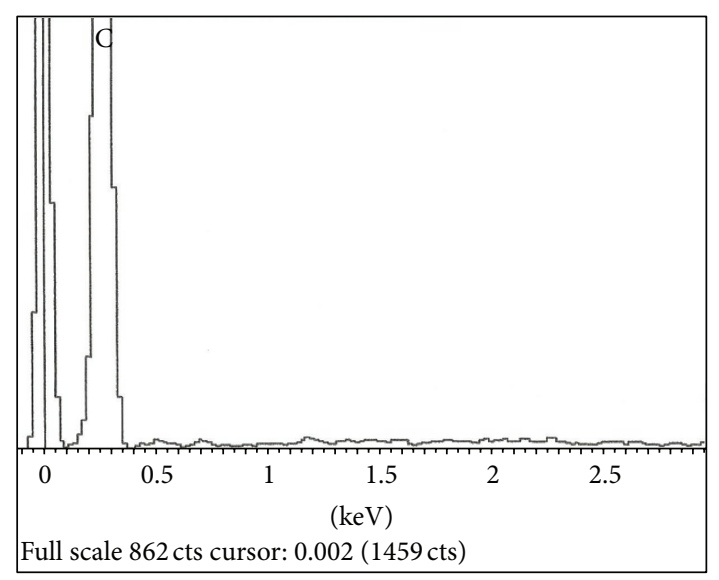

FIgURE 3: The EDX result of carbon nanospheres powder.

into fine powder, labeled deoiled asphalt, and kept under dry condition in desiccators. All chemicals used in the study were in AR grade.

The experimental setup for preparing CNS is shown in Figure 1. The system that consisted of a quartz reactor tube (I.D. $30 \mathrm{~mm} \times 90 \mathrm{~cm}$ long) was heated by an electrical tube furnace with a temperature controller. The deoiled asphalt powder (200 mesh) described above was placed in conical flask and heated up to $250^{\circ} \mathrm{C}$ under argon flow gas. The vapor produced was blown through the furnace zone using argon as a carrier and protective gas at the same time. Catalyst $\mathrm{CO} / \mathrm{Al}_{2} \mathrm{O}_{3}$ was placed in a porcelain boat and then located at the middle of quartz tube. The argon gas was introduced into the reactor at a flowing rate of $\left(20 \mathrm{~cm}^{3} / \mathrm{min}\right)$. The system was then ramped at $5^{\circ} \mathrm{C} / \mathrm{min}$ to reaction temperature (typically $900^{\circ} \mathrm{C}$ ) and held at the final temperature for $2 \mathrm{~h}$ before cooling 
TABLE 2: Granular cumulation distribution of CNS.

\begin{tabular}{|c|c|c|c|c|c|c|c|c|}
\hline $\begin{array}{l}\text { Diameter } \\
(\mathrm{nm})<\end{array}$ & Volume (\%) & $\begin{array}{c}\text { Cumulation } \\
(\%)\end{array}$ & $\begin{array}{c}\text { Diameter } \\
(\mathrm{nm})<\end{array}$ & Volume (\%) & $\begin{array}{c}\text { Cumulation } \\
(\%)\end{array}$ & $\begin{array}{c}\text { Diameter } \\
(\mathrm{nm})<\end{array}$ & Volume (\%) & $\begin{array}{c}\text { Cumulation } \\
(\%)\end{array}$ \\
\hline 30.00 & 0.64 & 0.64 & 120.00 & 10.19 & 42.04 & 190.00 & 2.55 & 84.71 \\
\hline 60.00 & 0.64 & 1.27 & 130.00 & 6.37 & 48.41 & 200.00 & 2.55 & 87.26 \\
\hline 70.00 & 3.82 & 5.10 & 140.00 & 9.55 & 57.96 & 210.00 & 3.18 & 90.45 \\
\hline 80.00 & 7.64 & 12.74 & 150.00 & 5.73 & 63.69 & 220.00 & 4.46 & 94.90 \\
\hline 90.00 & 5.10 & 17.83 & 160.00 & 7.64 & 71.34 & 230.00 & 3.82 & 98.73 \\
\hline 100.00 & 8.28 & 26.11 & 170.00 & 5.73 & 77.07 & 240.00 & 1.27 & 100.00 \\
\hline 110.00 & 5.73 & 31.85 & 180.00 & 5.10 & 82.17 & & & \\
\hline
\end{tabular}

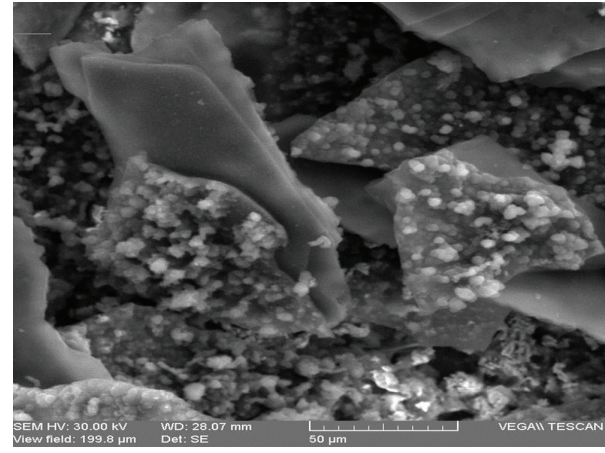

(a)

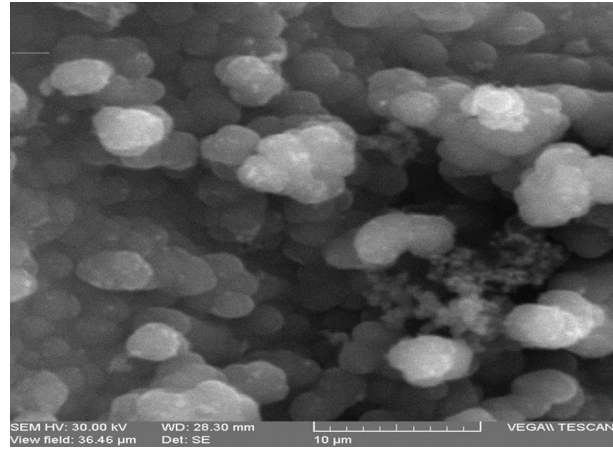

(b)

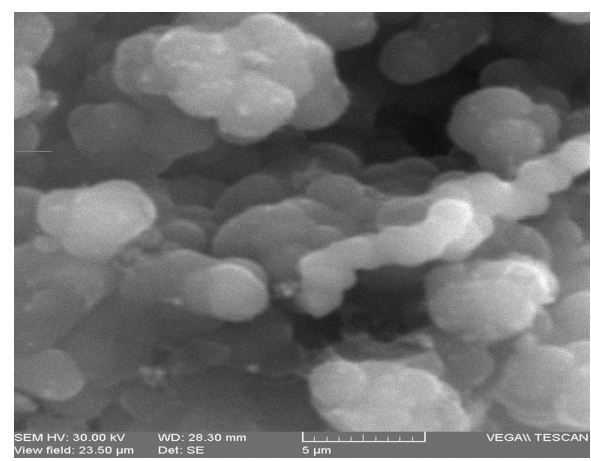

(c)

FIGURE 4: (a) Scanning electron Microscope (SEM) spectra of carbon nanospheres produced from Iraqi deoil asphalt directly after collection from the surface of CVD reactor. (b) SEM image of CNS. (c) SEM image of agglomerated CNS.

back to room temperature in argon gas. A large amount of black material was formed on the interior wall of quartz tube and was then collected, crushed, and milled to the final product. This prepared material was then characterized without further purification.

2.3. Characterization of CNS. Size and surface topography of the drop coated film on glass substrate were investigated using atomic force electron microscopy (AFM) with contact mode (NP10), and a silicon probe over scan size of $10 \mu \mathrm{m}$ was used.

The surface of the particle was observed by scanning electron microscope (SEM) and DES for chemical analysis. Standard automated powder diffractometer (XRD) was used with $\mathrm{Cu} \alpha$-radiation, and pure silicon powder as standard was employed to observe the structure of (CNS). BET measurement was conducted at $77 \mathrm{~K}$ on a sorptometer with a continuous adsorption procedure.

\section{Results and Discussion}

Iraqi deoiled asphalt has been adapted as a carbon precursor to prepare CNS under mild conditions, to our knowledge, which has never been reported in the literature. After being heated, asphalt would decompose, resulting in a large amount of small molecules and carbonaceous species. The preliminary results presented here lead one to believe that asphalt is another ideal main source for making carbon nanoparticles, though the mechanism involved in the process differs greatly from the scheme reported by [11].

As it is well known, asphalt thermally cracked to carbon when subjected to sufficient heat in inert atmosphere. This carbon is usually amorphous as it can be detected from the 


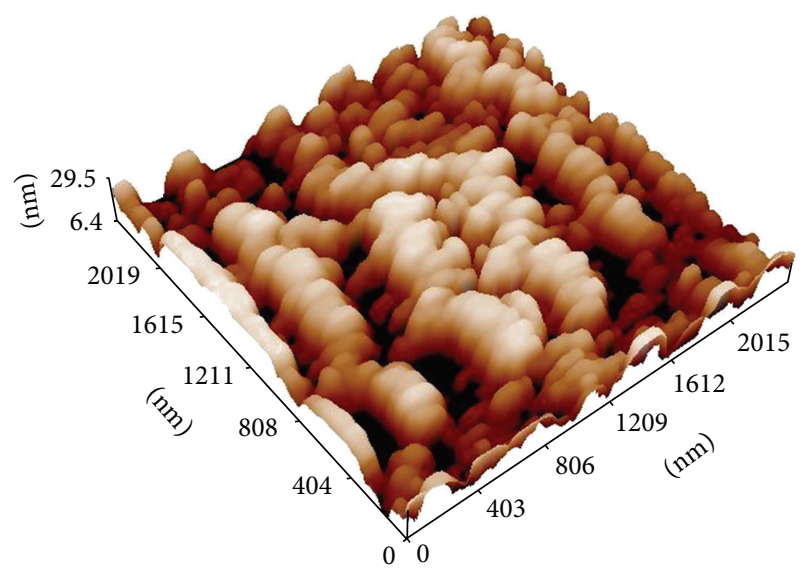

Figure 5: AFM scan results of CNS in glass surface show a threedimensional view of CNS in a $2400 \mathrm{~nm} \times 2400 \mathrm{~nm}$ scan area.

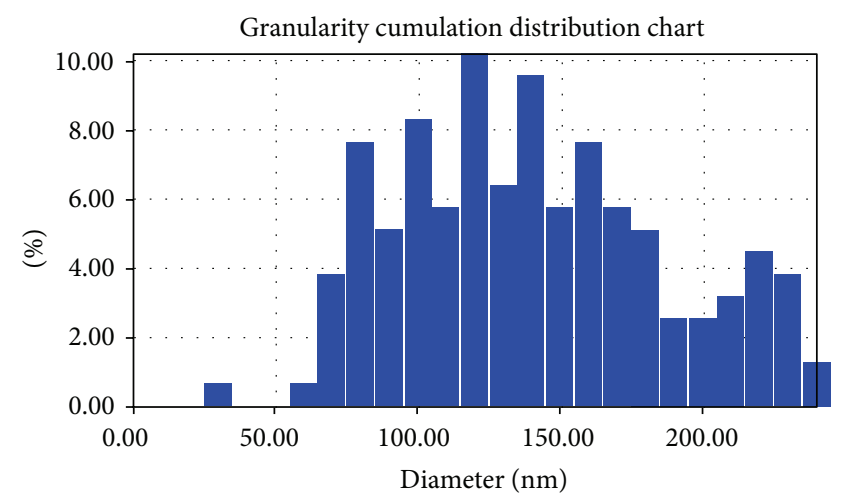

FIGURE 6: Granularity cumulation distribution chart of CNS.

$\mathrm{X}$-ray diffractogram shown in Figure 2. This is due to the low temperature of heating zone (i.e., $900^{\circ} \mathrm{C}$ ) which is not enough for the graphitization all of the deposited carbon.

The two peaks shown in Figure 2 are the characteristic peaks of amorphous carbon corresponding to (002) and (100) lines, respectively. There are no peaks of other materials in this XRD pattern, probably suggesting the high purity of the product. This result was confirmed by chemical analysis of product using EDX as in Figure 3 which shows a very well defined presence of carbon (94\%) in specimens subjected to temperature of $900^{\circ} \mathrm{C}$ for a period of 2 hours. Running the experiment without catalyst gives a low yield of CNS production. The production rate is increased by a factor of two in the presence of $\mathrm{CO} / \mathrm{Al}_{2} \mathrm{O}_{3}$ catalyst material, and a high portion of carbon clusters is deposited on interior surface of quartz tube, suggesting the roles played by catalyst in deciding the production rate of the CNS.

In order to investigate the surface morphology of nanospheres specimen, the surface was examined by SEM and AFM techniques. Figure 4(a) shows the SEM images of typical morphology of the carbon clusters consisting of carbon nanospheres directly after removal from the interior surface of quartz tube. While Figure 4(b) shows carbon nanospheres with a spherical shape obtained after flakes milling. Most of the particles seem to be agglomerated with each other as a sphere form as shown in Figure 4(b). No other structure such as carbon nanotubes or carbon flakes or fibers is detected. The uptake of nanospheres specimen was visualized by AFM type CSP scanning probe microscopy. The AFM image in Figure 5 clearly indicates the presence of nanospheres. The average diameter of carbon nanospheres of $130 \mathrm{~nm}$ was obtained as reported by granularity accumulation distribution chart of Figure 6 and listed in Table 2. It is expected that further purification and milling procedures will improve the particle size of carbon nanospheres.

The measurement of surface area by Brunauer-EmmettTeller (BET) shows an area around $370 \mathrm{~m}^{2} / \mathrm{g}$ from nitrogen adsorption-desorption isotherm. The material after some purification may be promising as lubricant oil, as a catalyst, in separation and adsorption for chemical and medical industries [6].

\section{Conclusions}

(1) The CNS with high purity have been successfully obtained by CVD method using Iraqi deoiled asphalt as a carbon source.

(2) The yield of CNs is strongly dependent on catalyst material.

(3) The CNS are clearly observed by SEM and the results are confirmed by the AFM indicating the presence of CNS with average diameter of $130 \mathrm{~nm}$.

\section{Acknowledgments}

This work was supported by a research grant from the Arab Science and Technology Foundation (ASTF) to whom the authors' thanks are due. The authors also thank the head of Chemical Engineering Department/University of Technology Professor Dr. Thamer J. for providing research space and support.

\section{References}

[1] P. G. Collins, A. Zettl, H. Bando, A. Thess, and R. E. Smalley, "Nanotube nanodevice," Science, vol. 278, no. 5335, pp. 100-103, 1997.

[2] I. Mochida, C.-H. Ku, and Y. Korai, "Anodic performance and insertion mechanism of hard carbons prepared from synthetic isotropic pitches," Carbon, vol. 39, no. 3, pp. 399-410, 2001.

[3] M. Endo, C. Kim, K. Nishimura, T. Fujino, and K. Miyashita, "Recent development of carbon materials for Li ion batteries," Carbon, vol. 38, no. 2, pp. 183-197, 2000.

[4] H. Fujimoto, A. Mabuchi, K. Tokumitsu, and T. Kasuh, "Relationship between the charge capacity of a turbostratic carbon anode for a Li secondary battery and its structure," Carbon, vol. 38, no. 6, pp. 871-875, 2000.

[5] M. B. Shiflett and H. C. Foley, "Ultrasonic deposition of highselectivity nanoporous carbon membranes," Science, vol. 285, no. 5435, pp. 1902-1905, 1999.

[6] T. Kyontani, "Control of pore structure in carbon," Carbon, vol. 38, pp. 269-286, 2000.

[7] M. Shao, Y. Ni, Y. Tong, G. Qian, and X. Wei, "Preparation of hollow carbon nanospheres at low temperature via new reaction 
route," Journal of Solid State Chemistry, vol. 178, no. 3, pp. 908911, 2005.

[8] K. Szota, A. Lesniewskia, J. Niedziolka et al., "Sol-gel processed ionic liquid-hydrophilic carbon nanoparticles multilayer film electrodeprepared by layer-by-layer method," Journal of Electroanalytical Chemistry, vol. 623, no. 2, pp. 170-176, 2008.

[9] A. Jaworek, "Micro- and nanoparticle production by electrospraying," Powder Technology, vol. 176, no. 1, pp. 18-35, 2007.

[10] V. Chuprasov, M. Tret'yak, V. Toropov, S. Chizhik, and A. Solntsev, "Obtaining carbon nanoparticles with the use of electric-arc discharge between coaxial electrodes," Journal of Engineering Physics and Thermophysics, vol. 77, no. 3, pp. 647650, 2004.

[11] Y. Fan, G. Liu, X. Liu, and B. Xu, "Study on the controlled growth of carbon nanospheres from de-oiled asphalt," Journal of Materials Science, vol. 41, no. 16, pp. 5242-5245, 2006. 

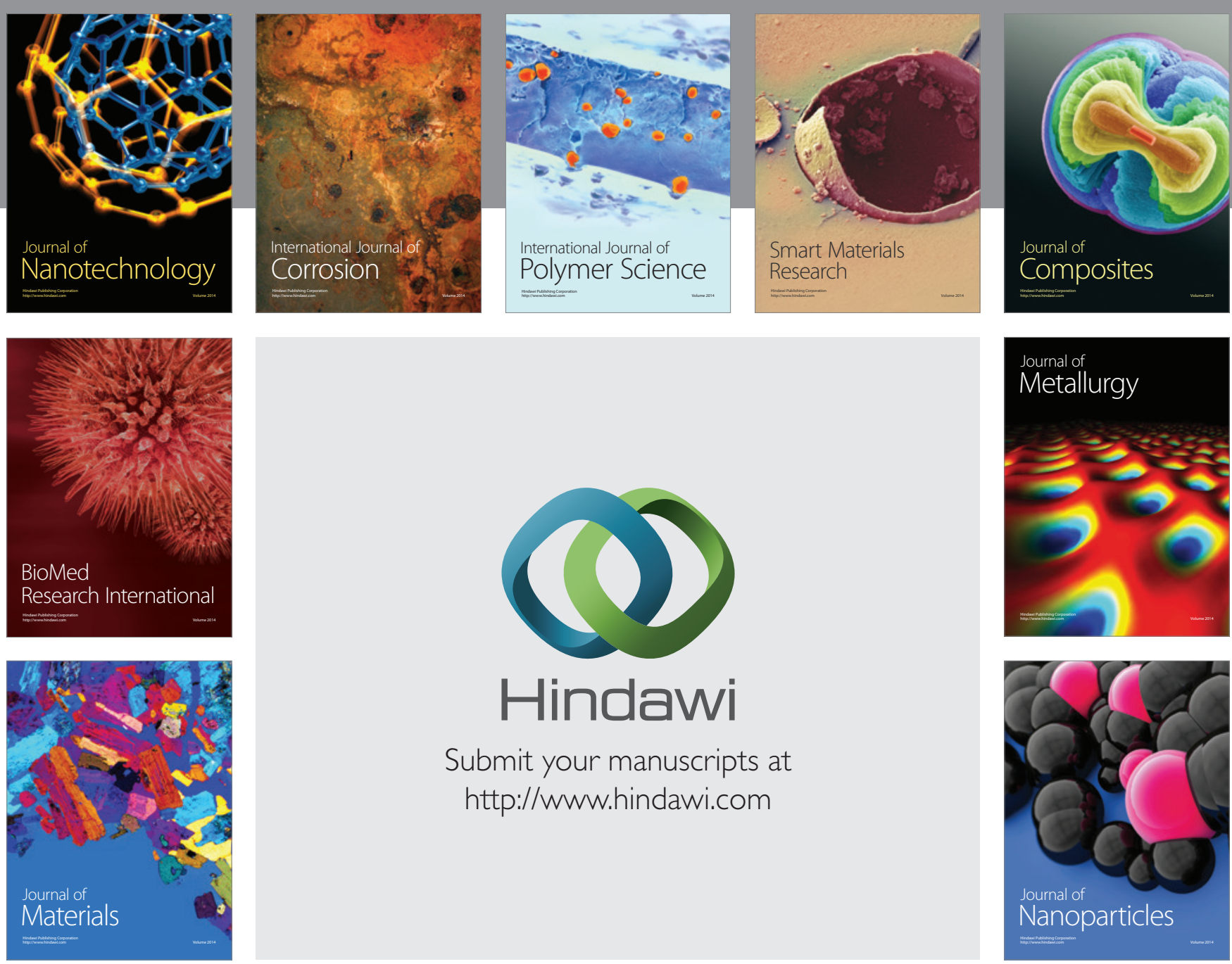

Submit your manuscripts at http://www.hindawi.com
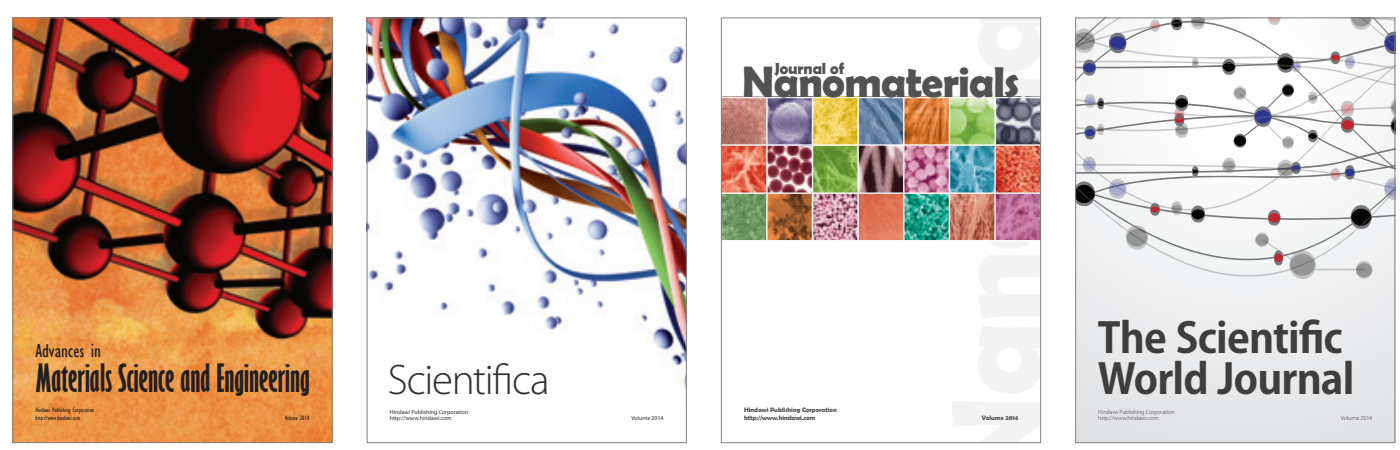

\section{The Scientific World Journal}
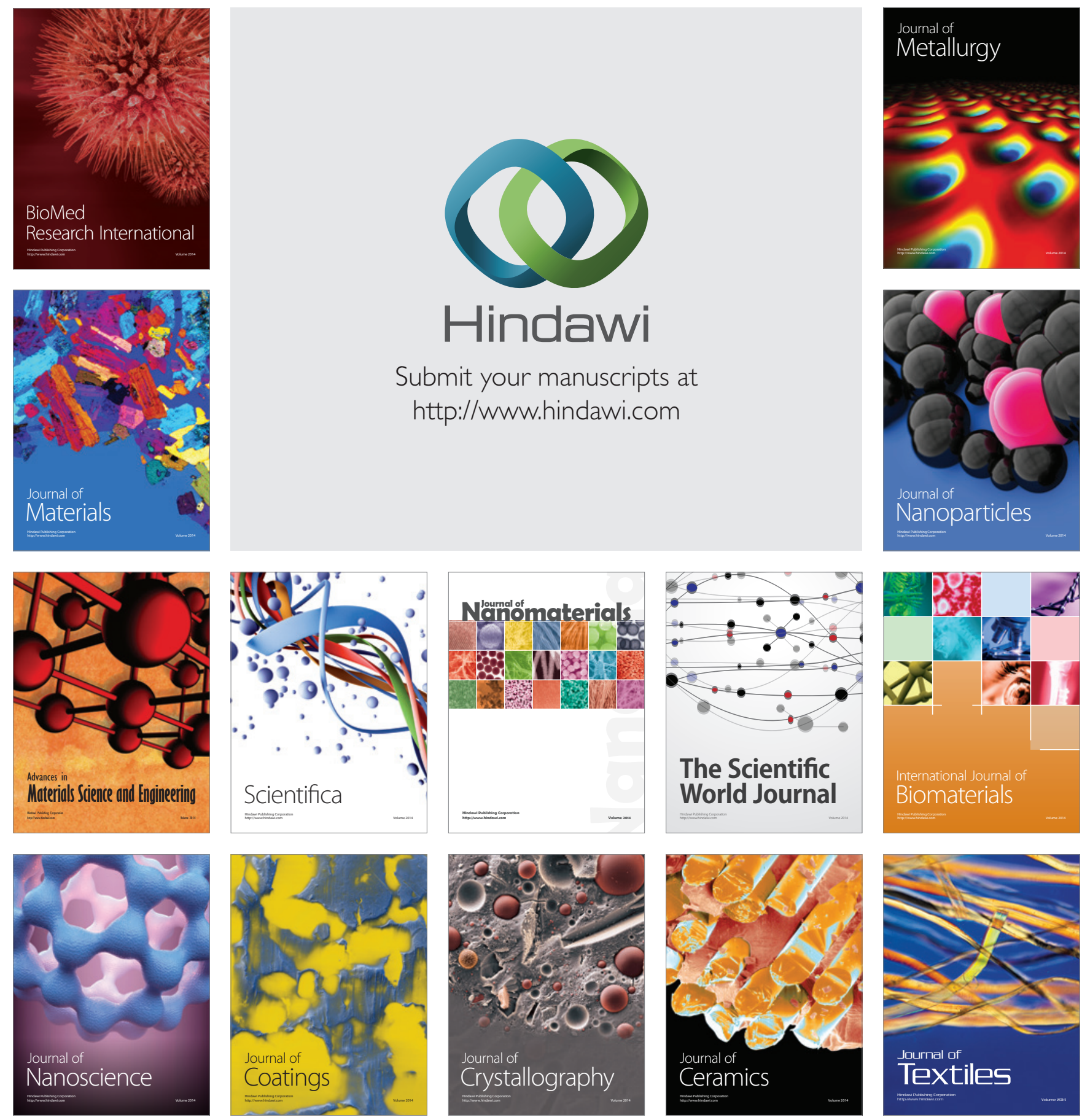